\title{
A POTENCIALIZAÇÃO DA CRIANÇA DIAGNOSTICADA COM TEA ATRAVÉS DA COMPLEXIFICAÇÃO DA RELAÇÃO PROJETO-FAMÍLIA
}

\author{
PETRY, D. S. A ${ }^{1}$, HOPPE, L. F², PELLANDA, C. M. N3
}

PALAVRAS-CHAVE: Complexidade. TEA. Tecnologia Touch. Acoplamento Tecnológico. Ontoepistemogênese. Família.

\section{RESUMO}

\begin{abstract}
Abordamos algumas provocações diante do projeto de pesquisa intitulado "Na Ponta dos Dedos: o iPad como instrumento complexo de cognição/subjetivação", pelas pesquisadoras da linha de frente dos atendimentos realizados com crianças diagnosticadas com Transtorno do Espectro Autista (TEA). Para tal, utilizamos o objeto técnico iPad, investigando o acoplamento humano-máquina, além do acoplamento sujeito-sujeito. Este projeto é amparado pelo Grupo de Ações e Investigações Autopoiéticas - GAIA aprofundando seus estudos nas emergências da ciência contemporânea, apostando na subjetividade e na formação humana complexa. Assim, o projeto vinculado traz em suas abordagens: a complexidade, o TEA, a tecnologia touch, o acoplamento tecnológico e a ontoepistemogênese - inseparabilidade viver/conhecer. Ao decorrer dos atendimentos das crianças - no Sistema Integrado de Saúde (SIS) nas dependências da UNISC, podemos perceber como a aceitação da família passou a influenciar no processo de aprendizagem e desenvolvimento das crianças. Assim, passamos a entender de outra forma essa relação projeto-família, procurando maneiras de deixar essa família cada vez mais próxima e ajudar a compreender essa criança como um ser autônomo e capaz, estando muito além de um diagnóstico. A pesquisa ainda está em andamento, portanto, compreende-se parcialmente que as crianças diagnosticadas com TEA obtiveram construções significativas de vínculos, melhoria na capacidade de trabalhar suas frustrações, melhoria da sensibilidade auditiva, um fluxo de viver mais autônomo, maior demonstração de sentimentos, etc. Sendo assim, o acoplamento tecnológico, apostando na tecnologia touch e nas relações projetofamília, potencializam o desenvolvimento do sujeito como um todo, sendo através de transformações cognitivas, subjetivas e/ou físicas.
\end{abstract}

\section{THE EMPOWERMENT OF CHILDREN DIAGNOSED WITH ASD THROUGH THE COMPLEXIFICATION OF THE PROJECT-FAMILY RELATIONSHIP}

KEYWORDS: Complexity. ASD. Touch Technology. Technological Coupling. Ontoepistemogênese. Family.

\begin{abstract}
We approached some provocations before the research project entitled "At the Fingertips: the iPad as a complex instrument of cognition/subjectivation", by the frontline researchers of the visits performed with children
\end{abstract}


diagnosed with Autism Spectrum Disorder (ASD). For this, we used the iPad technical object, investigating the human-machine coupling, in addition to the subject-subject coupling. This project is supported by the Group of Autopoietic Actions and Investigations - GAIA deepening its studies in the emergencies of contemporary science, betting on subjectivity and complex human formation. Thus, the linked project brings in its approaches: complexity, ASD, touch technology, technological coupling and ontoepistemogenesis - inseparability to live/know. During the care of children - in the Integrated Health System (SIS) in the premises of UNISC - we can see how the acceptance of the family began to influence the learning and development process of children. Thus, we began to understand in another way this project-family relationship, looking for ways to get this family closer and closer and help to understand this child as an autonomous and capable being, being far beyond a diagnosis. The research is still ongoing, therefore, it is partially understood that children diagnosed with ASD obtained significant constructions of bonds, improvement in the ability to work their frustrations, improvement of auditory sensitivity, a more autonomous flow of living, greater demonstration of feelings, etc. Thus, the technological coupling, betting on touch technology and project-family relationships, enhance the development of the subject as a whole, being through cognitive, subjective and/or physical transformations.

\section{INTRODUÇÃO}

0 presente artigo consiste em provocar e apresentar a relação projeto-família no decorrer dos estudos da pesquisa intitulada "Na ponta dos dedos: o iPad como instrumento complexo de cognição/subjetivação", por duas pesquisadoras que encontram-se à frente dos atendimentos desenvolvimentos com crianças diagnosticadas com Transtorno do Espectro Autista (TEA). Durante os atendimentos, utilizamos o iPad como instrumento técnico, provocando o acoplamento sujeito-sujeito e sujeito-máquina.

O seguinte projeto é apoiado pelo Grupo de Ações e Investigações Autopoiéticas - GAIA, formado no ano de 2006, na UNISC - Universidade de Santa Cruz do Sul, sob orientação da professora Dra. Nize Maria Campos Pellanda, professora do Programa de Pós-Graduação: Mestrado e Doutorado em Educação da UNISC Universidade de Santa Cruz do Sul, que busca analisar os estudos através das emergências da ciência contemporânea, pensando na formação humana complexa e na subjetividade. Este grupo tem como seu eixo de convergência a Educação e Complexidade, sendo assim, o projeto que está vinculado aborda questões como a tecnologia touch, o TEA, o acoplamento tecnológico, a complexidade e a ontoepistemogênese, termo que foi construído pelo GAIA para abordar a inseparabilidade de viver/conhecer.

Este projeto considera as relações e observações sensiveis para que consigamos entender além do que vemos, pois ações consideradas pequenas podem ter grandes significados para nossas pesquisas, pois durante os atendimentos dos sujeitos, que acontecem no Sistema Integrado de Saúde (SIS), na Universidade de Santa Cruz do Sul - UNISC, vemos como pode influenciar a aceitação das famílias no desenvolvimento e processo de aprendizagem dessas crianças com o diagnóstico. Podendo assim, compreender de outra maneira a relação projeto-família, buscando sempre diferentes maneiras dessa família se sentir acolhida, e ajudar essa família a perceber a criança além do diagnóstico, como um sujeito de particularidades, autônomo e capaz.

Nós utilizamos a tecnologia digital em versão touch para trabalhar com os sujeitos diagnosticados e romper com os paradigmas clássicos, fugindo da rotina e limitações das crianças. Sendo assim, proporcionando diferentes desafios para fugir das rotinas pré-determinadas e englobar os processos neurofisiológicos, pois 
vivemos em condições sociais e culturais rodeados de padrões no qual somos rotulados, mas partimos da problematização de que somos seres únicos e singulares. Sendo assim, a pesquisa busca entender os processos a partir das tecnologias digitais, através da subjetivação dos sujeitos com TEA. A partir disso, entendemos a cognição como "aquela faculdade que tem o ser humano (mas que também está presente em outros seres vivos) de, ao perceber a si mesmo e ao seu ambiente, se inventar a partir deste conhecimento". (PELLANDA; BOETTCHER, 2017, p. 71).

\section{FUNDAMENTAÇÃO TEÓRICA}

Para compreender melhor nossos objetivos, bem como conceitos e vivências, precisamos parar e refletir sobre tudo que acontece ao nosso redor, percebendo a circularidade que nos cerca e as relações presentes em nossas teias, e com isso como elas nos afetam, sendo de forma direta ou indireta. Dito isso, pensar sobre o Transtorno do Espectro Autista vai muito além de compreender o sujeito, portanto, passamos a olhar sensivelmente a teia que os compreende, sendo uma de suas âncoras, a família, sendo assim: será que está relação contribui no desenvolvimento do sujeito com o diagnóstico?

Durante o último ano no projeto, procuramos pensar como intervir de outras formas e como perturbar este sujeito de diferentes maneiras e não só dentro dos atendimentos na sala disponibilizada pelo SIS, passamos então a entrar de maneira mais direta nas demais relações que esta criança possui em sua circularidade, porém, primeiramente, é preciso compreender um pouco melhor sobre a complexidade, perspectiva esta que embasa nossas reflexões perante o grupo de pesquisa.

Como reflete Maturana, todo o ato de conhecer é viver, e ao vivermos estamos conhecendo, portanto, vivemos em uma sociedade onde nossas experiências são pessoais, partindo de dentro e não sendo impostas. Sendo assim, conhecer se torna uma ação "que permite a um ser vivo continuar sua existência em um determinado meio ao fazer surgir o seu mundo" (MATURANA; VARELA, 2002, p. 36), sabemos que há compreensões do TEA em que se engessam o modo de ser/estar na sociedade, mas conforme a pesquisa, 0 Transtorno do Espectro Autista é uma deficiência do neurodesenvolvimento que se apresenta através da socialização, comportamento e comunicação.

Apesar de pensarmos de tal forma, ainda vivemos em uma sociedade que busca constantemente por rótulos como se estes fossem necessários para que pudéssemos conviver de forma mais harmônica. Porém, a real necessidade de nossa atualidade é a empatia e o olhar sensível às especificidades do outros, é entendermos que todos nós somo singulares, possuindo ou não algum diagnóstico.

Devido a circularidade a qual estamos conectados, como já retratavam Maturana e Varela (2002), possuímos inúmeras maneiras de conhecer que não necessariamente estão vinculadas a ambientes ou momentos pré-estabelecidos, nossas vivências nos ensinam a compreender o mundo de uma forma mais sensível. De tal forma, viver e conhecer andam juntas, como complementos, pois na medida que vivemos conhecemos e vice-versa, bem como ser e fazer.

Compreendendo o conhecer desta forma, subentende-se que as construções são feitas através das trocas, sendo elas do sujeito com outro sujeito, com o ambiente ou com o objeto técnico que lhe é proporcionado, no caso de nossa pesquisa, o iPad. Assim, entendemos que podemos conhecer por diversos canais/meios e de 
forma diferentes, além de sermos singulares na nossa forma de agir no mundo, também somo singulares na forma de digerir as informações fornecidas por ele.

As trocas de vivências e as maneiras de conviver com o outro e do outro, faz com que nos transformemos interiormente de maneira espontânea, assim, nossas vivências e nosso modo de viver complementando o ambiente do outro, por isso, "o educar ocorre, [...], todo o tempo e de maneira recíproca" (MATURANA, 1997a, p. 29). Sendo assim, não podemos ver os sujeitos como máquinas pré-programadas e prontas para receber informações, são seres autônomos que agem, reagem e se modificam a partir de suas interações com o outro e ambiente de forma recíproca. Este, não está segregado em parte, mas compreende-se em um todo interagindo de forma social, biológica e cultural, visto que, "os indivíduos em suas interações constituem o social, mas o social é o meio em que esses indivíduos se realizam como indivíduos, [...] não há contradição entre o individual e o social, porque são mutuamente gerativos" (MATURANA, 1997b, p. 43).

A perspectiva complexa busca religar as conexões culturais entre a ciência e a humanidade, separadas com o tempo. Para isso, aposta-se nas provocações e problematizações do exterior, no caso de nossa pesquisa, nos pesquisadores da comissão de frente, como potencializadoras da construção de sujeitos cidadãos que possam auto-organizar-se frente esses desafios. Com isso, nos sujeitos, emergem questionamentos que possibilitam criar caminhos internos para a busca de suas respostas, a partir de suas vivências e trocas (MORIN, 2007).

Em complemento, como nós pesquisadores, Pretagalia, busca compreender a educação como totalizadora, sendo assim urgente repensarmos essas teias as quais cercam os sujeitos e como podemos construir de forma coletiva os ambientes, dito isso, é preciso repensar "a partir de uma visão totalizadora que a torne envolvida com as partes e os recortes, mas sempre em função das partes e de um todo uno, múltiplo e complexo, simultaneamente" (1995, p. 16). Ou seja, a educação constitui-se a partir das partes complementares das teias que nos cercam e nos compreendem como um todo, assim, é necessário construir essa rede apoio entre o projeto e a as famílias destes sujeitos, para depois irmos nos ligando com as demais partes dessa teia, trabalhando de forma conjunta em um mesmo objetivo, o desenvolvimento, sendo ele em todos os seus âmbitos.

As pesquisas vinculadas ao projeto: “Na ponta dos dedos: o iPad como instrumento complexo de cognição e subjetivação", nos mostram a importância do toque e consequentemente na ponta dos dedos, sendo essa uma grande entrada de sinapses construtoras de novos caminhos internos, assim, o toque na ponta dos dedos dispara mecanismos neurofisiológicos importantes (SANTAELLA, 2004), dito isso, apostamos no sistema háptico e na plasticidade neuronal através das perturbações táteis obtidas no toque do iPad, ou seja, na utilização da tecnologia touch, pois

0 maior sentido de nosso corpo é o tato. Provavelmente, é o mais importante dos sentidos para os processos de dormir e acordar; informa-nos sobre a profundidade, a espessura e a forma; sentimos, amamos e odiamos, somos suscetíveis e tocados em virtude dos corpúsculos táteis de nossa pele. (J. Lionel Tayler, The Stage os Human Life, 1921, p. 157)

Com isso, chegamos as percepções de Montagu (1988) sobre a pele, este o maior e mais sensível órgão do corpo humano, funcionando como um comunicador do externo com o interno, assim, constituindo-se o tato, primeiro sentindo a ser desenvolvido em um embrião. Acordado com isso, Santaella compreende a importância das combinações dos sistemas para a captação de informações, assim, 
Os olhos, ouvidos, nariz, boca e pele são modos de exploração, investigação e orientação, modos de atenção a tudo que é constante na estimulação mutável, capazes de isolar a informação pertinente. Longe de serem mutuamente exclusivos, sobrepõem-se e, na maior parte das vezes, estão focados no mesmo tipo de informação. (SANTAELLA, 2004, p.38)

Portanto, a tecnologia touch viabilizada a partir da sensibilidade da pele, dos dedos, potencializam os processos de aprendizagens, apresentando-se como grande preceptor do ambiente e transportador de informações, estas que podem construir novos caminhos para o desfecho de provocações realizadas pelo meio externo. Dito isso, o toque nos permite sentir e emergir nossas emoções, demonstrando nossas singularidades.

Já o sistema nervoso fica em uma parte escondida da pele, e é através dele que o sujeito percebe o ambiente, sendo assim, o mundo externo é percebido, onde possibilita que as informações sejam transportadas entre o sistema nervoso interno e o externo. É na pele que ficam marcadas nossas vivencias e através dela que emergem nossas emoções, onde possibilita a potencialização da nossa sensibilidade.

A epiderme é a camada mais superficial da pele, onde se encontra o sistema tátil, através dele que nossas terminações nervosas se encontram e ficam completamente ligadas ao tato e ao plexos nervosos, que são "os órgãos terminais específicos que respondem aos estímulos mecânicos de pressão e tensão. São mais especialmente numerosos na região dos dedos onde há as linhas de impressões digitais" (MONTAGU, 1988, p. 24).

Reconhecer a potencialidade do touch tornou-se de grande valia para o nosso grupo de pesquisa, visto que, demonstra-se um grande meio de construções significativas, proporcionando inúmeros efeitos no organismo, antes desconhecida, pois "existem diferenças bioquímicas significativas entre os seres humanos que se beneficiaram de uma estimulação tátil adequada e os que não se beneficiaram" (MONTAGU, 1988, p. 195-197). Acreditando nessa potência proporcionada pelo sistema tátil, pois a partir do contato é permitido que o sujeito perceba o ambiente e receba informações.

Nas extremidades do nosso corpo, mais precisamente na ponta dos dedos, se concentra a maior sensibilidade tátil, por isso, o tato permite compreender e trazer significados ao que tocamos, além de simplesmente agarrar as coisas, ou seja, é "o equipamento para sentir, tocar, apalpar é anatomicamente o mesmo equipamento para se fazer coisas, agir no ambiente. [...] Podemos tanto explorar quanto alterar o ambiente com as mãos" (SANTAELLA, 2004, p. 45).

Dito isso, a escolha da tecnologia touch como problematizadora, ruído, em nossa pesquisa, se dá como uma intervenção perturbadora, apostando em diferentes mecanismos de compreensão de mundo. Além disso, a tecnologia está invadindo o mundo que nos cerca e podemos utilizar desta invasão de uma forma potente que agregue em invés do contrário, assim, podendo transformar o imaginário e o abstrato em algo concreto e real, além de novas construções, possibilita "penetram no interior do corpo para não apenas reparar funções normais, mas também para ampliá-las, estimulá-las, transformá-las ou mesmo criar novas funções" (SANTAELLA, 2004, p. 29).

Para alinhar com nossas pesquisas sobre complexidade e a tecnologia touch, buscamos romper com as abordagens tradicionais do Transtorno do Espectro Autista - TEA que reforçam as estereotipias. Assim, priorizando o princípio da complexificação e o conceito de autopoiesis de Humberto Maturana e Francisco Varela (2001), a 
abordagem da auto-organização de Von Foerster (1996) e na teoria da aprendizagem pelo ruído de Henri Atlan (1992).

Apesar de em seus primórdios o autismo ser nomeado apenas com uma perda de contato com a realidade, com o passar dos anos outras crianças foram recebendo este diagnóstico e possuindo outras especificações além dos relacionados a comunicação social, ademais, nem todas demonstravam perdas cognitivas (GADIA, 2006). Nós, como pesquisadores, questionamos e nos perturbamos com as conceituações relacionadas ao TEA durante o passar dos anos, visto que, nos últimos anos está crescendo cada vez mais os diagnósticos de Transtorno do Espectro Autista.

Além disso, passamos a nos referir como um Transtorno Global do Desenvolvimento, assim, passando de Autismo para Transtorno do Espectro Autista, isso deve-se ao fato de não ser uma doença única, mas um distúrbio do desenvolvimento. Portanto, apresentada como principais características, estando todas associadas ou não: "déficits qualitativos na interação social e na comunicação, padrões de comportamento repetitivos e estereotipados e um repertório restrito de interesses e atividades" (GADIA, 2006, p. 423).

É comum que o sujeito com o diagnóstico tenda a se isolar, visto que possui dificuldade em entender abstrações, bem como, piadas, ironia e metáforas, desta forma, passa a interpretar de forma equivocada as situações que o cercam. Dito isso, dentre outras especificidades do diagnóstico,

o autismo [...] tem resistência a mudanças, insistência em determinadas rotinas, apego excessivo a objetos específicos e fascínio com o movimento de peças, principalmente com movimento de rotação. Muitas vezes, crianças com autismo que parecem estar brincando se preocupam mais em alinhar ou manusear os brinquedos do que em usá-los para sua finalidade simbólica. (GADIA, 2006, p. 424)

Além disso, os sujeitos diagnosticados com TEA possuem dificuldades com abstrações, ou seja, é necessário entender que coisas simples, como por exemplo, uma piada, precisa de adaptação para sujeitos com autismo, ou seja, é preciso entender as especificidades e também, que façam a utilização de materiais concretos para facilitar a compreensão das crianças, também é necessário observar fatores como a linguagem, a capacidade de adaptações e a responsabilidade social.

Ainda, pode haver indiferença afetiva, demonstrações equivocadas, dificuldade em trabalhos em grupos, falta de empatia emocional e a dificuldade em manter contato visual, sendo esta umas das primeiras características a ser percebida por quem o cerca. Já que estes sujeitos possuem essas singularidades, é preciso compreender que atitudes ou situações muito simples e corriqueiras em nosso cotidiano podem passar despercebidas ou possuírem dificuldade de interpretação por esses sujeitos, sendo assim, precisamos tornar as coisas o mais concretas possíveis de explicar detalhadamente o que está acontecendo, além disso, sempre realizar adaptações quando possível, bem como ser empático em relação ao outro.

\section{MATERIAIS E MÉTODOS}

Portanto, nossa pesquisa enfatiza o trabalho empírico e o desenvolvimento dos sujeitos atuantes, sendo eles, as crianças e os pesquisadores. Os atendimentos são uma ferramenta que desafia os sujeitos e as propostas empíricas possuem um importante lugar no projeto, pois cabe aos pesquisadores durante os atendimentos e após, potencializar os sujeitos através do acoplamento e dos ruídos externos, para que os sujeitos se autoorganizem. Sendo assim, as pesquisas realizadas contribuem para a construção dos conhecimentos, pois através 
dos estudos sobre a ontoepistemogênese em uma perspectiva complexa, temos um olhar mais sensível para os sujeitos diagnosticados com Transtorno do Espectro Autista (TEA), pois são mais do que um diagnóstico, não se restringem a uma rotulação externa.

Desse modo, aprendemos com Von Foerster (1996), que a ciência se completa em conjunto com o observado e o observador, pois os mesmos são seres humanos que se expressam, desenvolvem e falam de forma complexa, sendo assim, compreendemos que as vivências e os pensamentos não são separados, pois o processo pode ser uma possibilidade de interações e não que anula a subjetividade.

Aliás, no decorrer de cada atendimento, há novos desafios e possibilidades disponíveis no iPad para ambos, pesquisadoras e crianças, pois apostamos na potencialização e autonomia dos sujeitos. Esses atendimentos são filmados para posteriormente analisar e discutir com os integrantes da pesquisa, ao refletirmos sobre as imagens, podemos perceber pequenas particularidades que podem escapar no momento, além de poder comparar os diferentes pontos de vista entre os bolsistas da comissão de frente e os observadores, visto que, em muitos momentos movimentos e reações não fazem sentido para um grupo, mas são contextualizados pelo outro.

Os diários de bordo escritos por todos os pesquisadores envolvidos no projeto possibilitam criar uma linha do tempo daquele sujeito, registrando momentos, ações e reações, e tornando-se um material de pesquisa importantíssimo para os demais pesquisadores do grupo, mesmo que estes encontram-se em diferentes projetos vinculados, visto que, todos os projetos são embasados pela ontoepistemogenese e se complementam como um todo pertencente ao GAIA. Sendos assim, Heiz Von Foerster defende

a ideia de que o observador está incluído na realidade observada. Ele afirmou que o ruído
pode ser a fonte de processos auto-organizativos, os sistemas são fechados para a
informação e abertos para os fluxos de energia e o que o sistema percebe é através de
perturbações. (PELLANDA; BOETTCHER; PINTO (org), 2017, p. 250)

Além disso, as auto narrativas escritas pelos bolsistas sobre as suas vivências no projeto, tanto com as crianças, bem como pelos estudos teóricos os afetam, tornam de grande valia os encontros realizados e a sentimento de pertencimento ao grupo, assim, tornando os atendimentos mais significativos, visto que o foco não está apenas no sujeito observado, mas também nas transformações do pesquisador, sendo assim uma construção mútua e significativa.

\section{RESULTADOS E DISCUSSÃO}

A pesquisa ainda está em andamento, havendo resultados parciais, pois as crianças com Transtorno do Espectro Autista tiveram uma melhoria na capacidade de trabalhar com as frustrações, possuíram uma construção significativa de vínculo, melhoraram a sensibilidade auditiva, a demonstração dos sentimentos e reações, uma rotina mais autônoma, uma melhor relação com o espelho e a visualização do "eu”, a utilização de fotos e selfies, etc.

Entretanto, um grande resultado durante a vivência com os sujeitos dessa pesquisa, foi repensarmos a utilização do termo "autismo", pois utilizávamos "criança/sujeito autista", visto que estamos rotulando e condicionando o sujeito para o diagnóstico, compreendendo o mesmo somente por isso, sem suas potencialidades. Portanto, ao decorrer dos atendimentos, pesquisas e discussões, passamos a compreender a 
utilização do termo "sujeito com autismo", aparentemente parece pouco, mas a utilização do "com" na frase, nos faz entender a criança como um sujeito potente com apenas uma singularidade, buscando sempre a potencialização e autonomia dos mesmos.

Ao vivenciar as diferentes propostas da pesquisa, nós, como pesquisadoras, passamos por diversos momentos de complexificação, através da quebra de padrões, reconhecimento do eu e a reconstrução de novos conceitos. Nos reconhecemos como autoras da nossa própria vida, onde a participação no projeto "Na ponta dos dedos: o iPad como instrumento complexo de cognição/subjetivação" nos fez participar de novas vivências significativas, pois estamos nos constituindo a cada dia, com pequenos avanços durante os atendimentos e com as escolhas se qualificam e nos mostram a importância de romper com parâmetros pré-estabelecidos.

Encontramos muitos desafios e resistências durante esse processo, mas a tecnologia touch teve grande participação e auxilio da comunicação entre os sujeitos, além disso, ao compreendermos os sujeitos como seres únicos e singulares, ao construirmos vínculos com novas crianças e famílias que procurarem nosso projeto, construiremos novas perspectivas e descobriremos novas formas de provocação e problematização do ambiente externo que possibilitem novos caminhos internos na resolução de seus desafios, assim, contribuindo de maneiras diversas no processo de auto-organização daquela criança.

Sendo assim, através do uso da tecnologia e do acoplamento sujeito-máquina, as crianças com o diagnostico de Transtorno do Espectro Autista (TEA) podem construir diferentes possibilidades e novos caminhos neurais, possibilitando a comunicação e a expressão consigo mesmo e com o outro, ou seja, capaz de auxiliar na construção da sua autonomia através das relações sujeito-objeto e sujeito-sujeito, a partir do processo de autoorganização. Amenizando assim, consequentemente, uma das maiores especificidades do diagnóstico, a interação social e a comunicação, possuindo o uso da tecnologia como um meio de se conhecer e se expressar.

\section{CONCLUSÃO}

Ao refletirmos sobre nossas pesquisas, sendo elas leituras e vivências, começamos a compreender a importância da relação entre o projeto, carinhosamente apelidado como "Na Ponta do Dedos" e as famílias, visto que, durante este último ano passamos a dar maior relevância as teias conectivas que cercam os sujeitos. Desse modo, a tecnologia touch e o acoplamento tecnológico nas relações projeto-família potencializam a construção e desenvolvimento do sujeito, através de mudanças subjetivas, cognitivas e/ou físicas.

0 afunilamento dessa relação propiciou o resgate a autonomia dos sujeitos, assim, possibilitando que invés de protagonistas, tornarem-se autores de suas próprias histórias, ao os compreendermos desta forma, apostamos que todos os aspectos que o cercam estão relacionados a si, ou seja, a circularidade que o cerca está totalmente conectada a si e ao que o cerca, portanto, o definindo e construindo sua autonomia de forma simultânea (MATURANA, 1997a).

Portanto, o Projeto de Pesquisa vinculado busca compreender os processos de viver através da investigação do acoplamento humano-máquina por meio de tecnologias digitais, apostando na tecnologia touch, perante ao processo de subjetivação dos sujeitos, bem como, compreender como as relações da família afetam no desenvolvimento deste sujeito.

De tal forma, a aceitação do diagnóstico, bem como da aposta na autonomia de seus filhos, e o momento ao qual as famílias passaram a ver o seus filhos com um olhar mais sensível, entendendo- o como um 
sujeito autônomo, capaz e potente, possibilitaram que estes tenham mais confiança em suas escolhas e mais liberdade para demonstrarem quem são, tornando mais leve tanto para a família, quanto para as crianças.

Além disso, o alinhamento entre o manejo desses sujeitos no projeto e em casa também contribuíram no seu desenvolvimento, visto que, "[...] a criança autista, sem dúvidas, é capaz de aprender, cada uma de sua maneira, desde que receba um programa individualizado de intervenções. [...] Tais condutas devem ser uniformes na escola, no lar e na sociedade". (GADIA, 2006, p. 431)

\section{AGRADECIMENTOS}

Agradecemos aos nossos familiares, principalmente aos nossos pais, que em todos momentos nos deram o apoio e incentivo necessário, além de toda compreensão quando não pudemos comparecer a eventos familiares para nos dedicarmos as pesquisas.

Obrigada, professora Nize, por contribuir com a nossa trajetória acadêmica, profissional e pessoal, pela confiança depositada e a incansável dedicação. Obrigada por ser tanto.

Ao grupo de pesquisa, GAIA, agradecemos imensamente a dedicação e participação de cada um, pois suas pesquisas contribuíram para os nossos avanços dentre o projeto "Na Ponta dos Dedos", além disso, por nos incentivarem em todas as vezes que fomos convidados a representar o grupo perante palestras, rodas de conversas e cursos.

Agradecemos também, a Universidade de Santa Cruz do Sul - UNISC, por proporcionar momentos como este, ajudando-os a crescer como acadêmicos, profissionais, pesquisadores e acima de tudo, como seres humanos.

Porém, nada faria sentindo se não agradecêssemos as famílias dos sujeitos, por significar tanto essa pesquisa. Obrigada por nos permitirem entrar em suas intimidades e além de conviver e intervir com seus filhos, que pudéssemos problematizar e provocá-los também.

Por fim, agradecemos imensamente à Deus, por nos dar força, saúde, disposição e muita persistência durante o desenvolvimento do projeto e desse artigo, pois, sem ele, não seria possível.

\section{REFERÊNCIAS}

ATLAN, H. Entre o cristal e a fumaça. Rio de Janeiro: Zahar, 1992.

PELlANDA, N. M.C.; BOETTCHER, D. M.; PINTO, M. M. Viver/conhecer na perspectiva da complexidade: experiências de pesquisa. Santa Cruz do Sul: EDUNISC, 2017.

VON FOERSTER, H. Visão e conhecimento: disfunções de segunda ordem. In: SCHNITMAN, Dora Friedman (Org.). Novos paradigmas, cultura e subjetividade. Porto Alegre: Artes Médicas, 1996.

MONTAGU, A. TOCAR: o significado humano da pele. São Paulo: Summus Editorial, 1988.

SANTAELLA, L. Corpo e Comunicação: sintoma da cultura. São Paulo: Paulus, 2004.

GADIA, C. Aprendizagem e Autismo. In. ROTTA, N. T. Transtornos da Aprendizagem: Abordagem Neurobiológica e Multidisciplinar. Porto Alegre: Artmed, 2006. 
MATURANA, H. R.; VARELA, F. J. A Árvore do Conhecimento. As Bases Biológicas da Compreensão Humana. São Paulo: Editora Palas Athena, 2002.

MATURANA, R. Humberto. Ontologia da realidade. Belo Horizonte: UFMG, 1997b.

MATURANA. De máquinas e seres vivos: autopoiése - a organização do vivo. Porto Alegre: Artes Médicas, $1997^{a}$. PETRAGALIA, I. C. Edgar Morin: a educação e a complexidade do ser e do saber. Petrópolis: Editora Vozes, 1995. MORIN, E. Educação e Complexidade: Os Sete Saberes e outros ensaios. São Paulo: Editora Cortez, 2007. 